\title{
PENGARUH PENAMBAHAN SERAT ECENG GONDOK PADA KUAT TEKAN PAVING BLOCK K-200
}

\author{
Muttaqin Fauzin Istighfarin ${ }^{1}$; Rasio Hepiyanto ${ }^{2}$ \\ ${ }^{1,2}$ Fakultas Teknik Universitas Islam Lamongan \\ email : muttaqinfauzin08@gmail.com; waringinmegah_rasio@yahoo.com
}

\begin{abstract}
This study aims to know and analyze how strong the influence of additional water hyacinth fiber to the compressive strength of K-200 paving block. Method used in this study is experimental method, with the comparison of mix design reffering to the comparison of concrete quality mixture $K-200$ (SNI 7394-2008). The result is K-200 paving block decreases its compressive strength after given the mixture of water hyacinth fiber. The precentage of the lowest decrease is in the 0,2 mixture of $55,69 \%$ and the highest decrease is in the mixture of 0,8 with the decline presentage of of $82,39 \%$. The score of compressive strength for each test object is: Normal of 209,53 kg/ $\mathrm{cm}^{2}, 2 \%$ of $92,86 \mathrm{~kg} / \mathrm{cm}^{2}, 4 \%$ of $84,53 \mathrm{~kg} / \mathrm{cm}^{2}, 6 \%$ of $58,33 \mathrm{~kg} / \mathrm{cm}^{2}$, and $8 \%$ of $36,90 \mathrm{~kg} / \mathrm{cm}^{2}$. The relationship of non- linear regression can be seen in $R^{2}=1$ on polinomial orde 4. Paving block with with code objects test "Normal" classified as in the quality of paving block B with compressive strength of $209,53 \mathrm{~kg} / \mathrm{cm}^{2}(17,03 \mathrm{Mpa})$, while for paving block with extra water hyacinth fiber, it is below the compressive strength standard according to SNI 03-0691-1996.
\end{abstract}

Keywords: Rigid Pavement, Paving Block, Water Hyacinth, Compressive Strength.

\section{ABSTRAK}

Penelitian ini bertujuan untuk mengetahui dan menganalisis seberapa kuat pengaruh penambahan serat eceng gondok terhadap kuat tekan paving block K-200. Metode yang digunakan dalam penelitian ini adalah metode eksperimen, dengan perbandingan rujukan desain campuran dengan perbandingan kualitas campuran beton K-200 (SNI 7394-2008). Hasilnya adalah paving block K-200 mengurangi kekuatan tekannya setelah diberi campuran serat eceng gondok. Prosentase penurunan terendah adalah pada campuran 0,2 sebesar 55,69\% dan penurunan tertinggi pada campuran sebesar 0,8 dengan presentase penurunan sebesar 82,39\%. Skor kuat tekan untuk setiap benda uji adalah: Normal 209,53 kg $/ \mathrm{cm}^{2}, 2 \%$ dari $92,86 \mathrm{~kg} / \mathrm{cm}^{2}, 4 \%$ dari $84,53 \mathrm{~kg} / \mathrm{cm}^{2}, 6 \%$ dari $58,33 \mathrm{~kg} / \mathrm{cm}^{2}$, dan $8 \%$ dari $36,90 \mathrm{~kg} /$ $\mathrm{cm}^{2}$. Hubungan regresi nonlinier dapat dilihat pada $R^{2}=1$ pada polinomial orde 4. Paving block dengan dengan kode objek tes "Normal" diklasifikasikan sebagai kualitas paving block B dengan kekuatan tekan $209,53 \mathrm{~kg} / \mathrm{cm}^{2}$ (17,03 Mpa), sedangkan untuk paving block dengan serat eceng gondok ekstra air, berada di bawah standar kuat tekan sesuai SNI 03-0691-1996.

Kata Kunci: Perkerasan Kaku, Blok Paving, Eceng gondok, Kekuatan Kompresif.

\section{PENDAHULUAN}

Kata beton dalam bahasa inggris berasal dari bahasa Latin concretus yang berarti tumbuh bersama atau menggabungkan menjadi satu. Dalam bahasa Jepang digunakan kata kotau-zai, yang arti harafiahnya material-material seperti tulang; mungkin karena agregat mirip tulangtulang hewan. (Tjokrodimulyo, 2007) Beton merupakan pencampuran dari semen, agregat halus, agregat kasar dan air dengan suatu perbandingan tertentu. Jika ingin membuat beton 
berkualitas baik, dalam arti memenuhi persyaratan yang lebih ketat karena tuntutan yang lebih tinggi, maka harus diperhitungkan dengan seksama cara-cara memperoleh adukan beton(beton segar/fresh concrete) yang baik dan beton (beton keras / hardened concrete) yang dihasilkan juga baik. Beton yang baik ialah beton yang kuat, tahan lama/awet, kedap air, tahan aus, dan sedikit mengalami perubahan volume (kembang susutnya kecil). Dari penelitihan terdahulu ternyata eceng gondong ini memiliki kandungan senyawa kimia yang sangat berperan penting dalam pembuatan semen, Penggunaan bahan tambahan kimia sesuai kebutuhan untuk memperkuat hasil beton pun dilakukan demi menghasilhan beton yang berkualitas baik. Eceng gondok dimanfaatkan untuk dibuat serbuk yang akan digunakan sebagai campuran pembuatan beton (Hidayat,2011). Tujuan Penelitian ini adalah Untuk mengetahui fungsi dan pembuatan eceng gondok sebagai bahan serat selulosa yang digunakan sebagai bahan tambah untuk meningkatkan kuat tekan beton.

\section{METODE PENELITIAN}

Penelitian ini menggunakan metode penelitian eksperimental laboratorium yaitu mengadakan kegiatan percobaan untuk mengadakan suatu hasil. Tujuan eksperimen ini yaitu untuk membandingkan hasil yang telah didapat dalam penelitian dengan syarat - syarat yang ada. Waktu dan tempat penelitian ini akan dilakukan di Laboratorium Teknik Sipil Universitas Islam Lamongan J1. Veteran No.53 A Lamongan. Penelitian ini dilakukan mulai bulan Februari 2018 sampai selesai.

\subsection{Pelaksanaan Penelitian}

Bahan

Bahan - bahan yang digunakan dalam pembuatan benda uji adalah:

a. Semen Portland

b. Agregat Kasar (Kerikil)

c. Agregat Halus (Pasir)

d. Serat Alami Eceng gondok e. Air

Peralatan

Peralatan yang dibutuhkan dalam penelitian ini adalah :

a. Alat pencampur bahan :

- Concrete mixer

- Sekop /sendok semen

b. Cetakan silinder beton 
c. Mesin tekan hidrolis untuk menguji kuat tekan beton

\subsection{Pengujian Bahan Susun Campuran Beton}

Pada tahap ini dilakukan dan pemeriksaan bahan penelitian yaitu Semen, Agregat, Serat Eceng gondok dan Beton. Pemeriksaan dilakukan untuk mengetahui sifat - sifat bahan apakah memenuhi standart spesifikasi yang telah di tentukan. Pengujian bahan susun campuran beton dengan menggunakan standar yang telah ditetapkan dan berlaku di Indonesia terdiri dari :

a) Penyelidikan Bahan Semen :

1. Percobaan Konsistensi Normal Semen (ASTM C 187-86)

2. Percobaan Berat Jenis Semen (ASTM C 188-89)

3. Percobaan Waktu Mengikat dan Mengeras Semen (ASTM 119-92)

b) Penyelidikan Bahan Pasir :

1. Pengujian Kadar Air Agregat (ASTM C 556 - 89)

2. Percobaan Berat Jenis Pasir (ASTM C 128-93)

3. Percobaan Air Resapan Pasir (ASTM C 128-93)

4. Percobaan Bobot Isi dan Rongga Udara (ASTM C 188-89)

5. Percobaan Analisa Saringan Pasir (ASTM C 136-95a)

c) Penyelidikan Bahan Batu Pecah

1. Percobaan Kelembapan Batu Pecah (ASTM C 566-89)

2. Percobaan Berat Jenis Batu Pecah (ASTM C 127-88-93)

3. Percobaan Air Resapan Batu Pecah (ASTM C 127-88-93)

4. Percobaan Berat Volume Batu Pecah (ASTM C 29-91)

5. Percobaan Analisa Saringan Batu Pecah (ASTM C 136-95a)

d) Pemeriksaan Serat Eceng gondok

Serat eceng gondok yang digunakan adalah eceng gondok yang diproses sendiri oleh peneliti sehingga menjadi serat eceng gondok yang dibutuhkan.

\subsection{Tahap Pembuatan Serat dari Enceng Gondok}

1. Pengambilan enceng gondok dari daerah sungai di Kecamatan Deket Kabupaten Lamongan.

2. Pembersihan enceng gondok dengan air bersih.

3. Eceng gondok dipotong-potong antara $5-10 \mathrm{~cm}$

4. Setelah enceng gondok dipotong-potong kemudian eceng gondok di gilingkan di tempat penggilingan.

5. Selesai digilingkan, kemudian serat eceng gondok dijemur sampai benar-benar kering. Variasi penambahan serat eceng gondok yang digunakan sebesar $2 \%, 4 \%, 6 \%$ dan $8 \%$ dari berat semen. 
Kemudian pembuatan benda uji dan penambahan serat eceng gondok pada masing - masing variasi dilakukan 3 kali sesuai dengan umur beton. Setiap pengujian terdapat 3 benda uji untuk setiap varian.

\subsection{Proses Perawatan Beton}

1. Setelah 24 jam dari proses pencetakan beton, cetakan beton dibuka perlahan-lahan dan benda uji silinder beton diambil

2. Benda uji kubus beton diletakkan dalam suatu bak air, dan dibiarkan sampai sehari sebelum waktu pengetesan untuk dikeluarkan dari bak (pengeringan)

3. Pada waktu pengetesan, benda uji yang telah dikeluarkan dari bak dan mengering ditimbang beratnya setelah itu diukur dimensinya

4. Kemudian benda uji dicapping / diratakan dengan larutan belerang pada bidang tidak rata

5. Permukaan yang dicapping dari benda uji diletakkan di atas, dan benda uji siap dites Langkah tersebut berlaku untuk benda uji yang berumur 7 hari.

\section{HASIL DAN PEMBAHASAN}

Berdasarkan metode pengujian referensi standart yang berlaku, penulis melakukan pengujian di Laboratorium Universitas Islam Lamongan (UNISLA). Pengujian karakteristik material halus dan kasar merupakan pengujian awal yang di lakukan agar mengetahui karakteristik agregat halus dan kasar sebelum melakukan mix design beton yang mengacu pada SNI.

Dari data yang telah diperoleh selama pengujian, maka dilakukan perencanaan rancang campur (Mix Design SNI 03-2834-2000) pada beton dengan memanfaatkan serat alami eceng gondok, dalam pengujian tersebut beton merujuk pada beton mutu sedang dengan prosentase bervariasi pada komposisi semen yang dikurangi oleh serat alami eceng gondok. Benda uji yang digunakan adalah silinder dengan ukuran tinggi $30 \mathrm{~cm}$ dan diameter $15 \mathrm{~cm}$ sebanyak 3 buah untuk setiap sample campuran beton untuk diujikan kuat tekan beton pada umur 7 hari. Diharapkan dari hasil penelitian ini, peneliti dapat mengetahui hasil kuat tekan beton

\subsection{Pencampuran Beton Segar (Mix Design) Data Perencanaan}

1. Deviasi standart $\quad$ : Beton Non Struktural

2. Jenis semen : Semen portland

3. Jenis serat $\quad$ : Serat alami eceng gondok

4. Jenis agregat kasar : Kerikil

5. Jenis agregat halus : Pasir

6. Mutu beton : : Beton Non Struktural 
7. Umur perawatan : 7 hari

8. Jenis benda uji : Silinder

Diketahui - Tinggi silinder $=30 \mathrm{~cm}$

- Diameter silinder $=15 \mathrm{~cm}(\mathrm{r}=7,5 \mathrm{~cm})$ Maka

Volume silinder

$$
\begin{aligned}
& =\pi \times \mathrm{r}^{2} \times \mathrm{t} \\
& =3,14 \times 7,5^{2} \times 30 \\
& =529,75 \mathrm{~cm}^{2} \\
& =5299 \times 10^{3} \times \mathrm{m}^{3} \\
& =0.0053 \mathrm{~m}^{3}
\end{aligned}
$$

\subsection{Pengujian Beton dan Kuat Tekan Beton}

Analisa data kuat tekan didapat dari hasil pengujian kuat tekan paving block, apakah dengan penambahan serat eceng gondok pada bahan campuran paving block dapat menambah kuat tekan pada paving block, data penelitian di lakukan pencatatan sebagai data penelitian. Rumus kuat tekan paving block

Kuat tekan $\left(\mathrm{kg} / \mathrm{cm}^{2}\right)=\frac{P}{A}$

\begin{tabular}{|c|c|c|c|c|c|}
\hline No & $\begin{array}{l}\text { soda } \\
\text { Bund a } \\
\text { qu! }\end{array}$ & $\begin{array}{c}\text { Berzt } \\
\text { (ki) }\end{array}$ & $\begin{array}{c}\text { Toking } \\
\text { Danger } \\
\text { grony }\end{array}$ & $\begin{array}{c}\text { Mex } \\
\text { Tels=n } \\
\text { ngen "y }\end{array}$ & 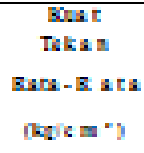 \\
\hline \multirow[t]{3}{*}{1} & $\mathrm{~N} 1$ & 3,00 & 30 & 130,00 & \multirow{3}{*}{146,67} \\
\hline & 2 & 3,00 & 30 & 150,00 & \\
\hline & 3 & 3,00 & 28 & 140,00 & \\
\hline \multirow[t]{3}{*}{2} & 2961 & 3,00 & 13 & 65,00 & \multirow{3}{*}{65,00} \\
\hline & 2 & 3,00 & 13 & 65,00 & \\
\hline & 3 & 3,00 & 13 & 65,00 & \\
\hline \multirow[t]{3}{*}{3} & $4 \% 1$ & 3,00 & 13 & 65,00 & \multirow{3}{*}{59,17} \\
\hline & 2 & 3,00 & 12,5 & 62,50 & \\
\hline & 3 & 3,00 & 10 & 50,00 & \\
\hline \multirow[t]{3}{*}{5} & $\operatorname{Bgh} 1$ & 2,90 & 9 & 45,00 & \multirow{3}{*}{40,83} \\
\hline & 2 & 2,90 & 7,5 & 37,50 & \\
\hline & 3 & 3,00 & 8 & 40,00 & \\
\hline \multirow[t]{3}{*}{5} & 8961 & 3,00 & 6,5 & 32,50 & \multirow{3}{*}{25,83} \\
\hline & 2 & 2,80 & 5 & 25,00 & \\
\hline & 3 & 2,90 & 4 & 20,00 & \\
\hline
\end{tabular}

Keterangan: $\mathrm{P}=$ Tekanan hancur (ton)

$\mathrm{A}=$ Luas penampang $\left(200 \mathrm{~cm}^{2}\right)$ Adapun hasil pengujian kuat tekan paving block hari ke 7.

Tabel 1: Hasil Pengujian Kuat Tekan Hari Ke -7

Sumber:Pengolahan Data Penelitian, 2018 
Dari tabel di atas dapat dilihat bahwa dengan penambahan serat eceng gondok pada campuran paving block dengan prosentase serat eceng gondok sebesar $2 \%, 4 \%, 6 \%$, dan $8 \%$ dari berat semen yang digunakan kesemuanya mengalami penurunan kuat tekan pada paving block. Kuat tekan tertinggi rata - rata pada paving block dengan tambahan serat eceng gondok adalah 65,00 $\mathrm{kg} / \mathrm{cm}^{2}$, sedangkan nilai terendah rata - rata adalah $25,83 \mathrm{~kg} / \mathrm{cm}^{2}$. Sedangkan paving block dengan campuran normal didapatkan hasil kuat tekan sebesar 146,67 kg/ $\mathrm{cm}^{2}$.

Pembahasan pada penelitian ini adalah menganalisa hasil pengujian kuat tekan paving block dengan tambahan serat eceng gondok. Adapun hasil dari penelitian kuat tekan paving block K200 dengan tambahan serat eceng gondok pada umur 28 hari, serta telah dilakukan analisa prosentase peningkatan ataupun penurunan adalah sebagai berikut:

Tabel 2: Hasil Pengujian Kuat Tekan Paving Block Umur 28 Hari

\begin{tabular}{cccc}
\hline No & $\begin{array}{c}\text { Kode } \\
\text { Benda Uji }\end{array}$ & $\begin{array}{c}\text { Tegangan } \\
\text { Hancur } \\
\left(\mathrm{kg} / \mathrm{cm}^{2}\right)\end{array}$ & $\begin{array}{c}\text { Prosentase } \\
\text { Penurunan } \\
(06)\end{array}$ \\
\hline 1 & $\mathrm{~N}$ & 209,53 & - \\
\hline 2 & $2 \%$ & 92,86 & 55,69 \\
\hline 3 & $4 \%$ & 84,53 & 59,66 \\
\hline 4 & $6 \%$ & 58,33 & 72,17 \\
\hline 5 & $8 \%$ & 36,90 & 82,39 \\
\hline & & & \\
\hline
\end{tabular}

3.3 Model hubungan penambahan serat eceng gondok dengan kuat tekan paving block Analisa regresi linier sederhana, untuk memperoleh suatu model regresi yang menggambarkan hubungan antara satu variabel bebas (penambahan serat eceng gondok) dan satu variabel terikat (kuat tekan paving block). Selanjutnya dalam penelitian ini yang menjadi variabel bebas (X) adalah penambahan serat eceng gondok, sedangkan variabel terikat (Y) adalah kuat tekan paving block. Hasil analisa regresi disajikan pada gambar 1. 


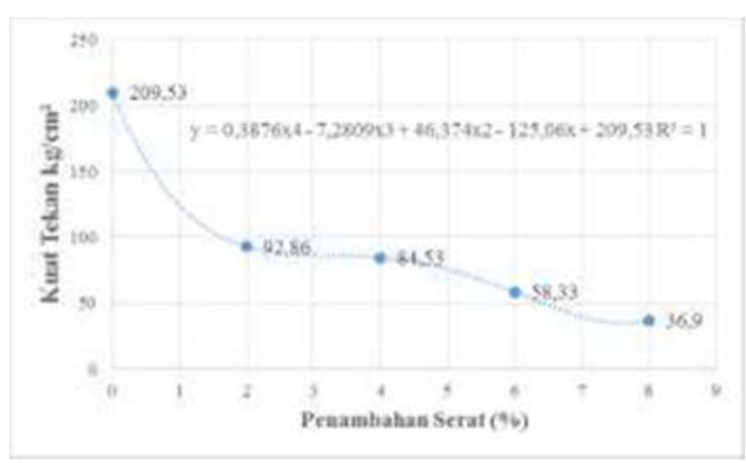

Gambar 1: Analisa Grafik Kuat Tekan Paving Block

Sumber : Pengolahan Data Penelitian, 2018

Pada gambar 1 adalah model regresi non linier yaitu model regresi polinomial orde 4 . Koefisien determinasi $\mathrm{R}^{2}$ bernilai 1 , yang artinya angka ini memiliki keterkaitan yang kuat antara penambahan serat eceng gondok dan kuat tekan paving block. Koefisien tersebut memperlihatkan bahwa pengaruh penambahan serat eceng gondok terhadap nilai kuat tekan paving block sebesar $100 \%$. Adapun hasil analisa grafik kuat tekan paving block dari model persamaan regresi polinomial dan hasil analisa persamaan regresi polinomial, dapat dilihat pada tabel 10 dan tabel 11 sebagai berikut:

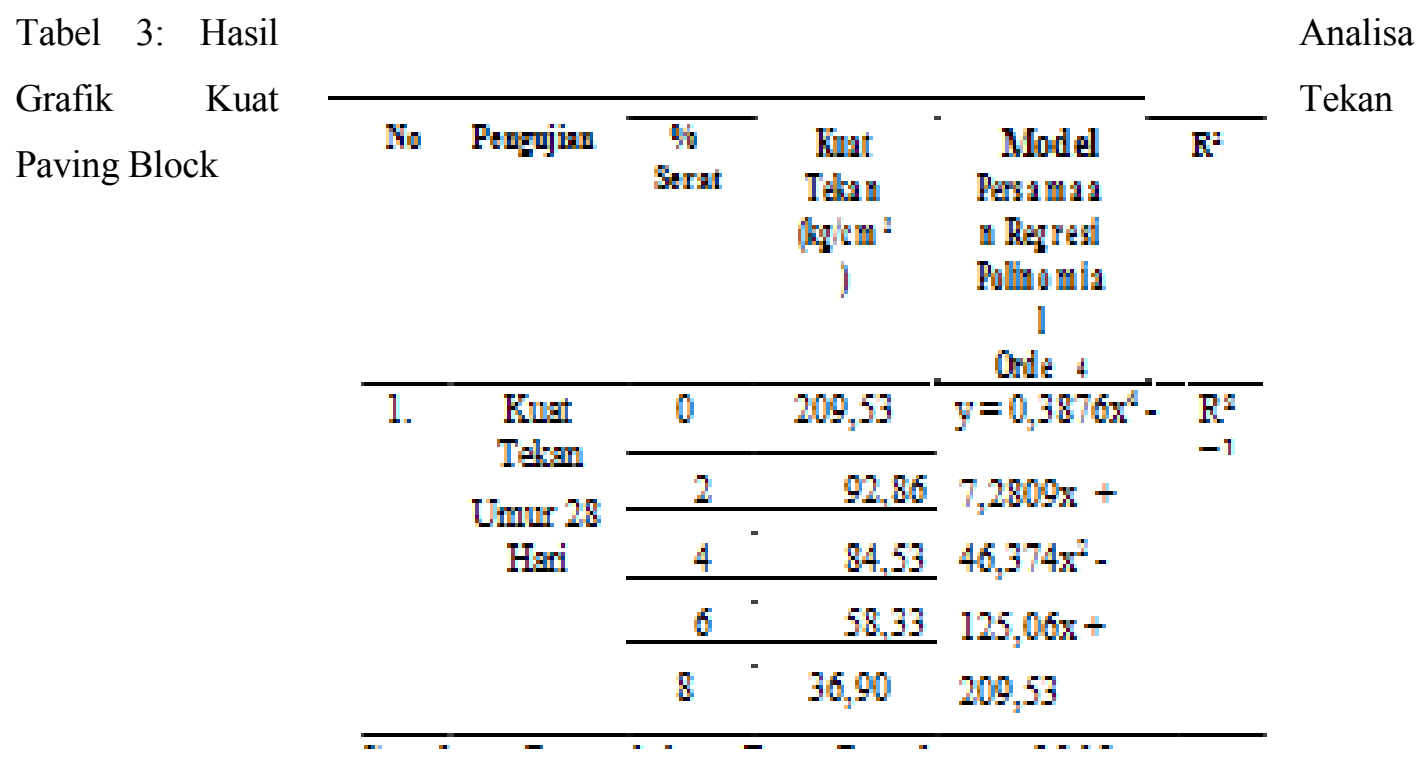

Sumber : Pengolahan Data Penelitian, 2018

\section{KESIMPULAN}

\subsection{Kesimpulan}

Paving block K-200 mengalami penurunan kuat tekan dengan bertambahnya campuran serat eceng gondok, prosentase penurunan terendah pada campuran 0,2 sebesar 55,69\% dan 
penurunan tertinggi pada campuran 0,8 dengan prosentase penurunan sebesar $82,39 \%$. Nilai kuat tekan masing - masing benda uji adalah; Normal sebesar $209,53 \mathrm{~kg} / \mathrm{cm}^{2}, 2 \%$ sebesar 92,86 $\mathrm{kg} / \mathrm{cm}^{2}, 4 \%$ sebesar $84,53 \mathrm{~kg} / \mathrm{cm}^{2}, 6 \%$ sebesar $58,33 \mathrm{~kg} / \mathrm{cm}^{2}$, dan $8 \%$ sebesar $36,90 \mathrm{~kg} / \mathrm{cm}^{2}$. Hubungan regresi non linier terlihat di $\mathrm{R}^{2}=1$ pada polinomial orde 4 . Paving block dengan kode benda uji Normal tergolong dalam mutu paving block B dengan kuat tekan 209,53 kg/ $\mathrm{cm}^{2}(17,03$ Mpa), sedangkan untuk paving block dengan tambahan serat eceng gondok tidak tergolong dalam mutu standar kuat tekan paving block karena nilai kuat tekannya dibawah standar mutu kuat tekan paving block (SNI 03-0691-1996).

\subsection{Saran}

Perlu adanya penelitian lanjutan tentang kuat tekan paving block dengan variasi penambahan serat eceng gondok yang berbeda, untuk mendapatkan nilai kuat tekan yang optimal. Perlu diadakan penelitian lebih lanjut metode pembuatan paving block dengan mesin vibrasi atau mesin hidrolis agar pencetakan paving block lebih maksimal. Perlu diadakan penelitian lebih lanjut pada metode pembuatan serat eceng gondok agar serat eceng gondok lebih mengikat dengan campuran paving block.

\section{REFRENSI}

[1] ASTM,Annual Book of ASTM Standart Volume 04.02 "Concrete and Aggregates", 2001

[2] ASTM C 29-91, Standard Test Method for Bulk Density ("Unit Weight") and Voids Aggregates.

[3] ASTM C 33-01, Standart Specification For Concrete Agregate. Philadelphia

[4] ASTM,C39, Compresive Strength of Cylindrical Concrete Specimens, (2002). Annual Books of ASTM Standards, Philadelphia-USA.

[5] ASTM C 127, Standard Test Method for Density, Relative Density (Specific Gravity), and Absorbtion of Coarse Aggregate.

[6] ASTM C 128-78, Standard Test Method for Density, Relative Density (Specific Gravity), and Absorbtion of Fine Aggregate.

[7] ASTM C 187-86, Normal Consistency of Hydraulic Cement

[8] ASTM C 188-89, Density Test of Hydraulic Cement

[9] ASTM C 188 - 95, Standard Test Method for Density of Hydraulic Cement. [10] ASTM C 191-92, Time of Setting of Hydraulic Cement by Vicat Needle

[11] ASTM C 566 - 89, Standard Test Method for Total Evaporable Moisture Content 
of Aggregate by Drying

[12] Badan Standarisasi Nasional. (2000). SNI 03-2834-2000, Tata Cara Pembuatan Rencana Campuran Beton Normal.

[13] Badan Standarisasi Nasional.. Hidayat, 2011. Pengaruh Penambahan Abu Sekam Padi Terhadap Kuat Tekan Beton K-225. Jurnal Aptek Edisi 2, Vol

[14] Universitas Pasir Pengarai, Riau. Tjokodimuljo, Kardiyono. 2004. Tegnologi Beton. Nafiri, Yogyakarta

[15] Fakultas Teknik Sipil, Pedoman Praktikum Beton, laboratorium Struktur Universitas Islam Lamongan. 